\title{
The Differing Effect of Gender and Clinical Specialty on Physicians' Intention to Use Electronic Medical Record
}

\author{
Hsin-Ginn Hwang ${ }^{1}$ Bireswar Dutta ${ }^{1}$ Hui-chuan Chang ${ }^{2}$ \\ ${ }^{1}$ Institute of Information Management, National Chiao Tung \\ University, Hsinchu, Taiwan \\ 2 Yuan General Hospital, Kaohsiung, Taiwan \\ Address for correspondence Bireswar Dutta, MS, Institute of \\ Information Management, National Chiao Tung University, No. 1001, \\ Daxue Road, East District, Hsinchu City, 30010, Taiwan \\ (e-mail: bdutta67@gmail.com).
}

Methods Inf Med 2019;58:e58-e71.

\begin{abstract}
Keywords

- electronic medical record

- technology acceptance model

- physician

- gender

- clinical specialty

Background The use of electronic medical record (EMR) is anticipated to bring benefits for patients, physicians, and organizations. But limited physicians' acceptance of EMR presents a serious threat to its effective implementation.

Objectives The current study incorporates technology acceptance model (TAM) with two antecedents, gender, and clinical specialty and one context-specific factor, financial incentives, to identify the factors that influence physicians' intention to use EMR in Taiwan. Methods The survey methodology was used to collect data from the physicians, working in the regional hospital that had implemented EMR system. A total of 119 out of 213 questionnaires returned in a response rate of $56 \%$. But four responses were considered ineffective due to missing values. The structural equation modeling (SEM) technique was employed to analyze the research framework.

Results The partial least squares (PLS) regression indicated that three factors perceived usefulness, financial incentives, and attitude toward using EMR significantly affect physicians' intention. But concerning perceived ease of use (PEOU), an insignificant path coefficient was reported. Additionally, regression analysis showed gender, and clinical specialty positively influenced physicians' intention to use EMR.

Discussion and Conclusions The proposed research framework contributes to the conclusive explanation for interpreting physicians' intention to use EMR. Physicians generally have a higher level of computer literacy. Therefore, the factor of PEOU could not be critical regarding adopting new health information technology (HIT). This study also brings perspectives from the gender, and clinical differences have primarily been missing in the literature of the physicians' intention to use HIT. In doing so, it infers how gender, and clinical specialty, may complement (and in some instances, reinforce) the influence of technological and attitudinal factors of HIT use. Thus, health care providers must take these factors into consideration in the development and validation of the theories regarding the intention to use EMR.
\end{abstract}

\section{Introduction}

It has greatly consented that the use of information technology (IT) in the health care sector offers great potential for improving the quality, efficiency, and effectiveness of the provided services, personnel, above all reduces the organi- zational expenses. ${ }^{1,2}$ Previous researchers even confirmed if hospitals did not adopt contemporary information systems (IS), they could lose the trust of their patients. ${ }^{3,4}$ Thus, hospital information systems (HIS) have gradually taken over traditional hospital operation procedures. ${ }^{4}$ received

January 7, 2019

accepted after revision

July 5, 2019
DOI https://doi.org/

10.1055/s-0039-1695718.

ISSN 0026-1270. @ 2019 Georg Thieme Verlag KG
Stuttgart · New York
License terms

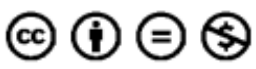


Electronic medical record (EMR) is regarded as the integration of several information tools (such as emergency information, electronic prescription, decision support system, digital imagery, and telemedicine) that might improve the uptake of evidence into clinical decisions. Using such evidence in everyday clinical practices might validate a safer and more effective health care system., ${ }^{5,6}$ Previous studies recommended several benefits of EMR for patients ${ }^{7,8}$ and one of the main benefits is to improve the quality of care resulting from accessing the patients' essential health records from different health care providers, which significantly can improve the coordination of the patients' care ${ }^{7,8}$ and the efficiency of health care practices. ${ }^{7,9}$

To determine the benefits of the EMR system, user adoption plays a major role. The existing literature indicated that many previous clinical system implementations had failed due to lack of user adoption. ${ }^{10,11}$ As the significant coordinator and provider of patient care, physicians' intention to use EMR determines the overall success of its implementation. ${ }^{12}$ So, the EMR acceptance by physicians is a primary condition to ensure that the expected benefits will be materialized. ${ }^{13}$ Although prior researches indicated that physicians would not consider a system that interferes with the way they care for patients or places limitations on the way they practice. ${ }^{14}$ Thus, understanding the factors influencing physicians' intention to use EMR is one of the critical elements in ensuring its optimal integration and ultimately measurable benefits within the health care system and patients.

To better cope with physicians' IS usage concerns, it is also significant to consider the gender and clinical specialty issues as previous researches explored that females are less interested in using new technology than males, a "gender gap,"15-18 as well as clinical differences, affect the physician's intention to use EMR. ${ }^{19,20}$ But, the outcomes reported in these studies remain inconsistent and inconclusive. Consequently, the present study includes gender and clinical specialty, for better understanding and predicting physicians' intention to use EMR. Thus, the primary aim of the current research is to explore the differences of gender and clinical specialty in perceptions and relationships among the factors influencing physician's intention to use EMR, and second to test the applicability and effectiveness of the extended technology acceptance model (TAM) for evaluating physicians' intention to use EMR in Taiwan. We are positive that the results of the present study can improve our current understanding regarding physicians' intention to use EMR in the hospital, and it will support both government and health care providers to determine the factors that may contribute to physicians' intention to use EMR more clearly.

\section{Literature Review}

\section{Electronic Medical Record in Taiwan}

The Taiwanese government has endorsed the following six dimensions of EMR: sharing, standards, infrastructure, applications, legislation, and security, ${ }^{21}$ alongside has taken several measures to promote EMR comprehensively after the initial startup had been successful in 2000 as a trial in a single hospital, ${ }^{22}$ that is, the government has propagated the Electronic Signatures Act to legitimately authorize the use of paperless signatures in 2001. In 2004, Article 69 of the Medical Care Act was amended to specify that medical care institutions that record and store medical records electronically are exempted from keeping a written copy. ${ }^{23}$ This provision is the formal legal base of EMR. In 2005, the department of health (DOH) introduced the "Regulations Governing the Production and Management of Electronic Medical Records in Medical Care Institutions," instructing that medical institutions may give back traditional written signatures with e-signatures while turning out EMR. ${ }^{23}$

In 2009, the DOH relaxed restrictions on the regulation of the time stamp to allow medical institutions to set up a trustworthy time-stamp management mechanism by themselves. Subsequently, receiving a time stamp from the Health care Certification Authority (HCA) of the DOH is no longer required which has significantly improved the delivery speed and convenience of e-signatures. ${ }^{23}$ By the end of 2011, 108 EMR reference templates for different types of medical records (such as outpatient physician order entry records, admission notes, and children's physical therapy assessment records) had been recommended on the web site. ${ }^{24}$ As stated by the reference model, real-world interhospital EMR mechanisms can be implemented. ${ }^{23}$ Thus, these developments support to promote the EMR system nationwide.

\section{Physicians' Intention to use EMR}

Understanding an individual's acceptance or rejection of IT is considered one of the most challenging concerns in IS research. ${ }^{25,26}$ Successful implementation of an IS depends immensely on the degree of consideration given to human concerns which have a certain effect on the process ${ }^{12}$ and one of the critical human concerns is resistance to change. Klaus and Blanton ${ }^{27}$ stated that the critical interference toward implementing successful IT projects within the organization is employees' resistance to change.

From the IT perspective, different groups have different cognitive biases. Hu et $\mathrm{al}^{28}$ reported that physicians differed significantly from other professional users in general competence, intellectual, and cognitive capacity, as well as work arrangement and nature. However, focusing on the potential adoption of IT by physicians is important for successfully running medical institutions. ${ }^{29,30}$

Yi et $\mathrm{al}^{31}$ stated that perceived improvement in performance from using IT intensely influenced physicians' intention to use the system in the health care sector. Chau and $\mathrm{Hu}^{29}$ explored that the significant role of perceived usefulness (PU) among physicians in fostering their intention toward using a new technology might be centered on physicians' utility-based perspective about using technology. In other words, physicians consider using new HIT while they perceive it has anticipated utility and might be contributory in their practices. According to Chang et $\mathrm{al}^{32} \mathrm{PU}$ exerted the most significant impact on physicians' intention to use clinical decision support systems (CDSS). Based on the study of Kijsanayotin et al, ${ }^{33}$ PU was the main determinant of behavioral intention to use HIT. Therefore, as long as health care professionals perceive the EMR 
system as an instrument to improve their patient care performance, they will be more influenced to use the system.

The findings of Hoque ${ }^{34}$ on mobile-health (mhealth) adoption based on TAM reported that perceived ease of use (PEOU), subjective norm, and PU had a significant positive influence on the users' intention to adopt mhealth services. Hu et $\mathrm{al}^{28}$ studied the applicability of the TAM in explaining physicians' decision to adopt telemedicine technology, and their findings supported that TAM was capable of providing a reasonable interpretation of physicians' intention to use telemedicine technology. Kim et $\mathrm{al}^{35}$ explored physicians' attitudes toward EMR adoption based on TAM and the Unified Theory of Acceptance and Use of Technology (UTAUT) model and their results found all the variables (performance expectancy, effort expectancy, social influences, facilitating conditions, and attitude) positively influenced the physician's intention to adopt EMR. Al-Adwan and Berger ${ }^{36}$ studied physicians' behavioral intention based on TAM and self-perceived variables (perceived threat [PT], PU, PEOU, and social influences), and they found all the variables had a positive effect on physicians' intention. Liu and Cheng ${ }^{37}$ explored physician's intention to adopt mobile-EMR based on the dual-factor model and they found PU, PEOU, and PT had the significant influence on physicians' behavioral intention to adopt mobile EMR. The previous study by Price ${ }^{38}$ found that the most significant factors influencing physicians' intention to use EMR were PEOU, PU, and perceived patient-record privacy.

Overall, previous researches have shown some support to use TAM as a theoretical model to examine physicians' intention to use EMR. Therefore, to better understanding of the factors influencing physicians' attitude and intention to use EMR system in Taiwan, a modified TAM with two antecedents, gender, clinical specialty and one context-specific factor, and financial incentive was proposed and tested.

\section{Gender}

Investigating individual's intention to use technology is yet another area in which gender differences have been overlooked. ${ }^{30}$ However, the present study additionally identifies the influence of gender on the relationship between determinants and users' behavioral intention to use. Podolny and James $^{39}$ explored the demographic variable, called gender, had been proved to influence the use of new technologies. Hing and Burt ${ }^{40}$ found that the United States suffered a gender gap with regard to IT usage which might discourage women from entering into IT as a profession. Although prior studies investigated the gender differences in computer-related attitudes and its use, limited researches had integrated gender as a personality trait factor in evaluating the physicians' intention to use the new IS. Gillard et $\mathrm{al}^{41}$ dealt directly with gender differences as they related to the resistance to the EMR systems and, more generally, HIS in general. Sykes et $\mathrm{al}^{16}$ stated that gender predicted the EMR system use. Moffat et $\mathrm{al}^{42}$ in their study, found that $41 \%$ of female general physicians (GP) were nonusers of the EMR system compared with $28 \%$ of male GP. According to the findings of Schwirian et al, ${ }^{43}$ gender differences influenced physicians' attitude to HIT use. Menon et $\mathrm{al}^{44}$ explored that several physicians were consenting to use HIT but differed by gender.

Although it was anticipated from previous literature that gender was a significant factor in association with IT, Chan et $\mathrm{al}^{45}$ did not find any difference in their study. Lai et $\mathrm{al}^{46}$ also did not observe any influence of gender on the translation of intention to the actual implementation of a system. According to the study by Loomis et $\mathrm{al}^{47}$ there were no statistically significant differences in gender between users and nonusers of the EMR system. Djalali et $\mathrm{al}^{48}$ stated that male primary care physicians (PCP) had shown higher levels of EMR adoption, while the opposite was spot-on for the remainder. ${ }^{49,50}$

Therefore, we can conclude that the outcomes reported in the previous studies concerning the gender differences in the context of physicians' intention for HIT adoption, especially the EMR system adoption, remain inconsistent and inconclusive. $\mathrm{Chu}^{51}$ stated that gender differences in the use of the technology must be cautiously examined, instead of only representing differences. Thus, making out the gender differences in the strength of the path coefficients could bring additional perception into conventional theories regarding gender concerns.

\section{Clinical Specialty}

The significant differences have been reported among different medical disciplines in terms of EMR adoption. The previous literature highlighted concerns that different clinical disciplines might have a differing level of compatibility with the current state of EMR. ${ }^{20}$ Previous studies supported the need for medical specialty-specific systems to come across the unique requirements of corresponding specialties. ${ }^{31-34}$ These unique needs come out variations in a standard workflow, information collection requirements, and clinical documentation methods along with disparities in standard clinical volume, billing, compliance necessities, and specialty-specific terminology. ${ }^{20}$

The previous study recommended that the ratio of information review of information entry was likely to vary by specialty. ${ }^{52}$ Grinspan et al ${ }^{53}$ explored the association between physician specialty and EHR adoption, using a retrospective serial cross-sectional study over time, and their findings reported that physician specialty was significantly associated with EHR adoption. Whitacre ${ }^{54}$ found that, generally, some types of practices had remarkably high-EMR adoption rates (such as multispecialty and radiology). Grove and Patel ${ }^{55}$ stated in their study that physicians in large multispecialty practices reported the lowest rates of adoption of EHR. On the other hand, Bhargava and Mishra ${ }^{52}$ did not find any significant result among different specialty.

Therefore, previous studies regarding the clinical specialty differences in the context of physicians' intention to HIT use, especially the EMR system usage, remain inconsistent and inconclusive. Gagnon et $\mathrm{al}^{13}$ asserted that specialty should be taken into account, while developing EHR implementation strategies for targeting physicians. As different specialties had expressed different ideas of how the EHR should function and what it should provide. ${ }^{56}$ 
As to meet the purpose of HIT requirements of all physician specialties in a better way, and determining whether such interdisciplinary differences exist, identifying the physicians' practice nature is imperative. Thus, it is reasonable that physicians' specialty might influence the strength of the relationship between the criterion and predictor variables of physicians' intention to EMR use.

\section{Financial Incentives}

Employing financial incentives is a renowned practice to improve individual's efficiency and performance in all kinds of work settings of which the health care system is no exemption. ${ }^{57}$ Due to the physicians' crucial role in coordinating patients' care, any impact employed on their function has a substantial consequence of the entire health care system. ${ }^{58}$ The exercise of remuneration and reward policies are increasingly recognized as influencing the productivity of health care. However, the use of financial incentives is one way by which health care organizations attempt to influence the physicians' behavior. But, thus far, the literature provided little evidence regarding the influence of financial incentives on the quality of care. ${ }^{59}$

Both Roski et $\mathrm{al}^{60}$ and Gosden et $\mathrm{al}^{61}$ supported the argument that financial incentives inevitably contributed intended behavior changes. Baron et $\mathrm{al}^{62}$ indicated that the lack of financial incentive was a crucial barrier to EHR adoption among physicians in the community in their study. Marshall and Harrison ${ }^{63}$ pointed out the over-reliance on financial incentives for improving quality of care and reported that financial incentives did not always result in behavior change as intended. They further claimed that the attractiveness of financial incentives is always not based on inclusive empirical evidence. Miller et al $^{64}$ reported that lack of financial incentive was one of the factors contributing to the low adoption rate of EHR in spite of the intensified interest among physicians. Programs such as "Ontario MD's EMR Adoption Program” provided financial support for family physicians, and physicians working in primary care to assist with converting from paper charts and records to EMRs, ${ }^{65}$ which boosted up physicians' adoption of EMRs in Canada. Burt and Sisk ${ }^{66}$ explored that financial incentive might reward practices that adopted the technology and improved the physicians' patient care for their use. Conrad and Perry ${ }^{67}$ indicated that financial incentives had an impact on clinical quality. As reimbursement policy might impact medical innovation through their influence on technology adoption, ${ }^{68,69}$ we explore its influence on physicians' intention to use EMR.

\section{Research Hypothesis}

\section{Model Development for Factors Influencing Health Care Technology Acceptance}

Davis $^{70}$ introduced the TAM and proposed a theoretical framework that explains the relationship between users' attitude and behavioral intentions. Based on this model, PU and PEOU are hypothesized to be the principal factors of users' acceptance. Both Yarbrough and Smith ${ }^{71}$ and Holden and
$\operatorname{Karsh}^{72}$ found that PU of IS was positively associated with physicians' attitudes toward IS tools if the tangible benefits of the IS were reasonably appreciated. In fact, PU was found to be a strong motivator for predicting health care professionals' attitudes toward IS in the patient care perspective. ${ }^{72-74}$ Conversely, previous studies also concluded that physicians, who perceived the system as easy to operate and useful, generally developed a positive attitude toward such a system. ${ }^{71-73}$

Davis $^{70}$ stated that there is a direct relationship between attitude and the use of IT, implying that users will intend to use an IT system when they evaluate it positively. Venkatesh et $\mathrm{al}^{25}$ reported that attitude toward using IT, as the second most significant predictor of the physician's intention to use telemedicine services and this finding supported the finding of the other studies investigating physicians' IS acceptance. ${ }^{25,75,76}$ Thus, the following three hypotheses based on the above discussion were proposed in this study:

$\mathbf{H}_{\mathbf{1}}$ PU positively influences physicians' attitude toward using EMR.

$\mathbf{H}_{\mathbf{2}}$ PEOU positively influences physicians' attitude toward using EMR.

$\mathbf{H}_{\mathbf{3}}$ Physician's attitude positively influences his/her intention toward using EMR.

EMR has the potential ability to improve the quality of health care. But, unless physicians perceive some personal benefits from using EMR, they might not be motivated to switch and stick to their traditional working processes. Both Miller and $\operatorname{Sim}^{77}$ and Vishwanath and Scamurra ${ }^{78}$ indicated that unless physicians perceived some personal incentives during the implementation of EMR, the adoption of EMR would not reach the expected level. Significantly, the incentives considered in the stated studies are mainly financial ones. Patel et $\mathrm{al}^{79}$ explored that financial concerns were the key barrier to adopting or using HIT by physicians. Yarbrough and Smith ${ }^{71}$ reported that the lack of financial incentives was a critical barrier to adopt and use EMR by physicians in their systematic review about technology acceptance in health care. Thus, the following hypothesis based on the above discussion was proposed in this study:

$\mathbf{H}_{\mathbf{4}}$ Financial incentives positively influence the physician's attitude toward using EMR.

Previous studies reported differences in the adoption of technology and related application between men and women. ${ }^{80,81}$ Research on technology usage between men and women revealed that men tended to exhibit a taskoriented attitude to show that they understood the usefulness of technology more effortlessly than women do. ${ }^{80}$ Existing literature also revealed that men tended to have more access to technologies than women. ${ }^{82}$ The findings of Dutta et $\mathrm{al}^{83}$ on the personal health record (PHR) acceptance found that both PU and PEOU had a stronger influence on female respondents than male respondents.

Different physician groups evaluate the usefulness of IS based on the assessment of how their needs are satisfied and how easy to use it. Except IS has an extensive attractiveness to the different clinical specialties (e.g., a 
diagnostic innovation), there will be resistance from specialties to the adoption of the system, as the system's perceived value is limited to a solitary clinical specialty. ${ }^{1}$ Melas et $\mathrm{al}^{19}$ used physician specialty as a moderator to examine the acceptance of clinical information systems among the hospital medical staff and reported the significant moderating effect of physicians' specialty. But it is logical that physicians' specialty may directly influence the strength of the relationship between criterion and predictor variables in the modified TAM. Based on the above discussion about relationships between personality traits, PU, and PEOU, the following hypotheses were proposed in this study:

$\mathbf{H}_{\mathbf{5}}$ Gender influences physician's PU of EMR.

$\mathbf{H}_{\mathbf{6}}$ Gender influences physician's PEOU of EMR.

$\mathbf{H}_{7}$ Clinical specialty positively influences physician's PU of EMR.

$\mathbf{H}_{\mathbf{8}}$ Clinical specialty positively influences physician's PEOU of EMR.

-Fig. 1 presents the research framework used for the current study.

\section{Materials and Methods}

\section{Questionnaire Design and Data Collection}

A questionnaire survey was employed to investigate the proposed theoretical framework. A questionnaire was developed with a range of items intended to evaluate each construct of the current study. A preliminary list of measurement items was primarily developed after reviewing the literature regarding TAM, gender, clinical specialty, and EMR. The instruments used for the current study comprised three sections. In the first section, the cover page, the purpose of the study, and the definition of EMR was provided. The second section considered the respondent's demographic information, including their gender and clinical specialty. The third section contained indicators concerning TAM (21 items) and financial incentives (five items). All the items were determined on a five-point Likert's scales, ranging from 1 for strongly disagree to 5 for strongly agree. Additionally, the content of the items was revised based on the results of a pretest and pilot study to enhance the reliability and validity of the items.
Both a pretest and a pilot study were conducted to validate the instrument. The pretest involved the following five experts: a professor of information management (IM) department, three doctoral scholars in the medical information field, and an employee who has been working in the health informatics department in the hospital for more than 10 years. Respondents were asked to explore the appropriateness of items, the format, and the wording of the scales. The pilot study involved twelve physicians self-selected from the study population. Based on the respondents' response at the pretest and pilot study, some items were modified to exhibit the survey's purpose more rationally and summarized in - Appendix A. The reliability of all items was acceptable (Cronbach's $\alpha$ is above 0.80 ) and items loaded in the confirmatory factor analysis were 0.70 or more. Thus, the instrument has endorsed reliability and content validity. - Appendix B presents the result of the pilot study.

\section{Research Setting}

In terms of hospital attributes, services, as well as the number of beds and physicians, the hospital employed in this study is able to refer as a typical regional hospital, located in Southern Taiwan with 654 beds, and 213 physicians available as of 2018. Prior to commencing the research, Institutional review board (IRB) consent was pursued and obtained from the hospital. All participants were given a consent form and information sheet which clearly explained the purpose of the current study. Respondents were also notified about their rights to withdraw participation at any time during the study.

Moreover, we presented our participants with a short description of how EMR works in general. This approach was chosen because of the following two reasons. First, to overwhelm any lack of knowledge about EMR that could have perceived among our participants reasonably of its continuous technological innovation, and second, to develop a reasonable conclusion about the prospective applications of EMR.

\section{Study Design and Sampling Distribution}

A total of 119 out of 213 physicians working in this hospital responded to this study. The response rate is around $56 \%$ (55.87\%). The number of physicians that responded the questionnaire might be not as large as in other nationwide survey

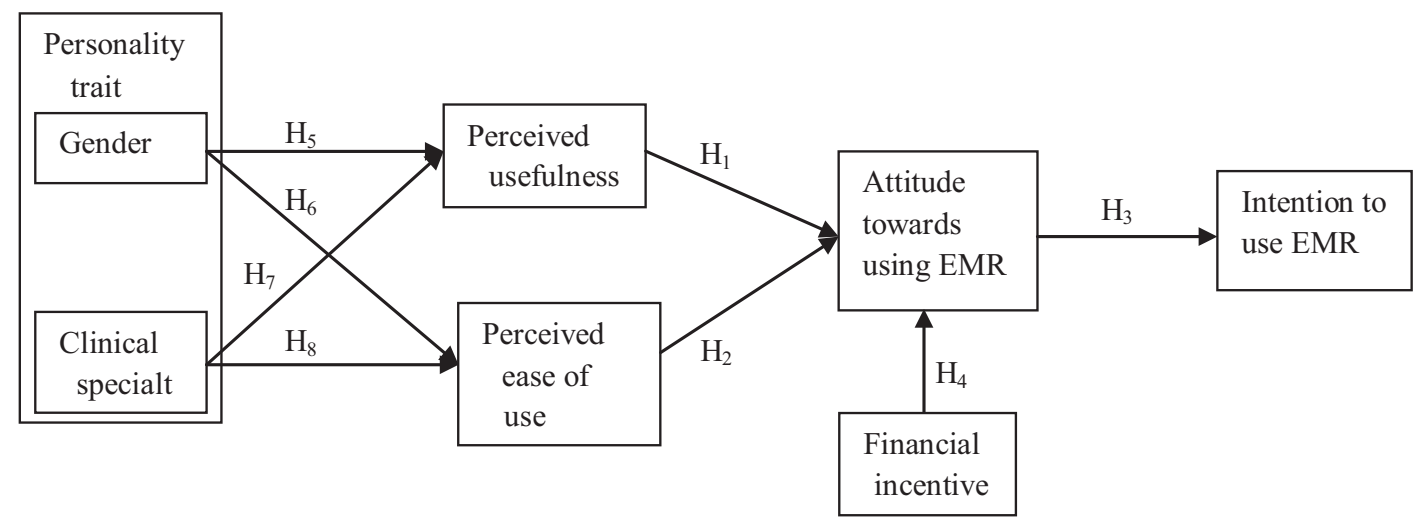

Fig. 1 Research framework. 
researches. However, the population of this study is limited on the one site, and furthermore it is over half of the physicians participate in this study. Additionally, it is representing that the number of physicians of the current study coincides with the previously published articles focusing on physicians' intention to adopt health care IT or IS. ${ }^{77,84-94}$ Moreover, to give an indication of the representatives of the study sample, the personality traits, gender, and clinical specialty, of the current study sample were compared with the nationwide sample of Taiwan. According to the Taiwan Medical Association report in 2011, the proportion of total male physicians in Taiwan was $83.7 \%{ }^{95}$ However, the majority of the current study sample is male (79.13\%), and specialty divisions correspond with national data of Taiwan. ${ }^{96}$ Thus, it is indicating that the distribution of physician in the current study coincides with the national physician distribution of Taiwan. In other words, the unbiased sample size of the current study lower down the sample biased and increases statistics power. Thus, it is indicating that the study hospital and the number of responses are acceptable compared with prior published researches.

\section{Data Analysis}

SPSS and PLS software were used for statistical analysis. Structural equation modeling (SEM) was used to analyze structural relationships due to three reasons. First, SEM is a multivariate technique that lets the simultaneous estimation of multiple equations. ${ }^{97}$ Second, SEM performs factor analysis and regression analysis in the single step, as SEM is used to test a structural theory. Third, PLS uses a nonparametric approach and is not limited by data normality. ${ }^{98}$ All constructs were modeled as reflective for the model tested. Data analysis was conducted on the two-step approaches suggested by Anderson and Gerbing. ${ }^{99}$ First, testing convergent validity and discriminant validity of the measurement model, and subsequently testing research hypotheses and structural model.

\section{Results}

\section{Demographic Data}

The current study collected 119 responses. Four responses out of 119 were considered unusable due to missing values. Therefore, we incorporated 115 valid responses for the final analysis. - Table 1 presents the demographics of respondents, and it points out that the respondents differ respectively in gender and clinical specialty.

\section{Tests of the Measurement Model}

Reliability analysis was tested using Cronbach's $\alpha$ and composite reliability (CR), and -Table 2 shows the results. Cronbach's $\alpha$ of each construct ranged from 0.961 to 0.980 which is above the recommended value of 0.7 by Hair et al. ${ }^{97}$ However, Nunnally ${ }^{100}$ suggested 0.90 as the "minimally tolerable estimate" for clinical purposes, with an ideal of 0.95 . But Steiner ${ }^{101}$ recommended 0.90 is the most likely indicated unnecessary redundancy. Thus, we consider CR values of the latent factors to measure the model's internal consistency. The $\mathrm{CR}$ value of each construct is above the
Table 1 Profile of survey respondents

\begin{tabular}{|l|l|l|l|}
\hline Item & Option & Count & Percentage (\%) \\
\hline Gender & Men & 91 & 79.13 \\
\cline { 2 - 4 } & Women & 24 & 20.87 \\
\hline $\begin{array}{l}\text { Clinical } \\
\text { Specialty }\end{array}$ & Surgery & 21 & 20.87 \\
\cline { 2 - 4 } & Medicine & 41 & 33.04 \\
\cline { 2 - 4 } & $\begin{array}{c}\text { Obstetrics and } \\
\text { gynecology }\end{array}$ & 8 & 6.96 \\
\cline { 2 - 4 } & Internal & 30 & 26.08 \\
\cline { 2 - 4 } & Pediatrics & 10 & 8.70 \\
\cline { 2 - 4 } & Others & 5 & 4.35 \\
\hline
\end{tabular}

recommended value of $0.7,{ }^{97}$ implying acceptable reliability and consistency of the measurement items of each construct.

Convergent validity of the scales was tested by using the following three standards suggested by Bagozzi ${ }^{102}$ : (1) loading of each indicator should be above $0.7,{ }^{103}$ (2) CR value of each indicator should be higher than 0.7 , and (3) average variance extracted (AVE) of each construct should be exceeded the variance because of the measurement error of that construct (i.e., AVE should be exceeded 0.50). As - Table 2 indicates, the factor loading of each item in the measurement model of the current study exceeded are well above 0.7 . The $C R$ values ranged from 0.971 to 0.983 . AVE values of constructs ranged from 0.868 to 0.921 , thus meeting each condition for convergent validity.

To test discriminant validity, Fornell and Larcker $^{103}$ recommended that the square root of the AVE of the construct should be higher than the estimated correlation shared between the construct and other constructs in the model. - Table 3 shows that the square root of AVE for each construct is higher than the correlation values of the construct, thus meeting the condition for discriminant validity.

\section{Tests of the Structural Model}

-Fig. 2 displays the standardized path coefficients, path significances, and variance explained $\left(R^{2}\right)$ by each path, all supported by the path analysis results, except H2. The coefficient for determination $\left(R^{2}\right)$ points out that the research framework interprets $33.5 \%$ of the variance associated with intention to use EMR and $82.8 \%$ of the variance associated with attitude toward using EMR is explained by PU, PEOU, and financial incentives. - Table 4 reports the results of the hypothesis test.

\section{The Effect of the Personality Traits (Gender and Clinical Specialty)}

The second section of the study investigates the influences of personality traits on EMR use decision. Multiple regression analyses were conducted to test the proposed hypotheses on the constructs: PU, PEOU, and personality traits (gender and clinical specialty). Both the personality trait variables, gender (H5 and H6) and clinical specialty (H7 and H8) were consistently found to predict both PU and PEOU. - Table 4 presents the relationships between personality traits and - Fig. 2 indicates $\beta$ values for each hypothesis. 
Table 2 Measurement model

\begin{tabular}{|c|c|c|c|c|c|c|}
\hline Constructs & Item & Loadings & No. of items & Composite reliability & Standardized Cronbach's $\alpha$ & AVE \\
\hline \multirow[t]{7}{*}{$\mathrm{PU}$} & PU1 & 0.941 & \multirow[t]{7}{*}{7} & \multirow[t]{7}{*}{0.983} & \multirow[t]{7}{*}{0.980} & \multirow[t]{7}{*}{0.894} \\
\hline & PU2 & 0.944 & & & & \\
\hline & PU3 & 0.933 & & & & \\
\hline & PU4 & 0.956 & & & & \\
\hline & PU5 & 0.949 & & & & \\
\hline & PU6 & 0.963 & & & & \\
\hline & PU7 & 0.931 & & & & \\
\hline \multirow[t]{4}{*}{ PEOU } & PEOU1 & 0.946 & \multirow[t]{4}{*}{4} & \multirow[t]{4}{*}{0.979} & \multirow[t]{4}{*}{0.971} & \multirow[t]{4}{*}{0.921} \\
\hline & PEOU2 & 0.971 & & & & \\
\hline & PEOU3 & 0.947 & & & & \\
\hline & PEOU4 & 0.973 & & & & \\
\hline \multirow[t]{6}{*}{ ATT } & ATT1 & 0.971 & \multirow[t]{6}{*}{6} & \multirow[t]{6}{*}{0.975} & \multirow[t]{6}{*}{0.968} & \multirow[t]{6}{*}{0.868} \\
\hline & ATT2 & 0.961 & & & & \\
\hline & ATT3 & 0.956 & & & & \\
\hline & ATT4 & 0.772 & & & & \\
\hline & ATT5 & 0.929 & & & & \\
\hline & ATT6 & 0.982 & & & & \\
\hline \multirow[t]{5}{*}{$\mathrm{FI}$} & Fl1 & 0.932 & \multirow[t]{5}{*}{5} & \multirow[t]{5}{*}{0.978} & \multirow[t]{5}{*}{0.972} & \multirow[t]{5}{*}{0.899} \\
\hline & $\mathrm{FI} 2$ & 0.941 & & & & \\
\hline & $\mathrm{Fl} 3$ & 0.962 & & & & \\
\hline & $\mathrm{FI} 4$ & 0.946 & & & & \\
\hline & $\mathrm{FI5}$ & 0.958 & & & & \\
\hline \multirow[t]{4}{*}{ INT } & INT1 & 0.953 & \multirow[t]{4}{*}{4} & \multirow[t]{4}{*}{0.971} & \multirow[t]{4}{*}{0.961} & \multirow[t]{4}{*}{0.894} \\
\hline & INT2 & 0.958 & & & & \\
\hline & INT3 & 0.949 & & & & \\
\hline & INT4 & 0.922 & & & & \\
\hline
\end{tabular}

Abbreviations: ATT, attitude toward using EMR; AVE, average variance extracted; EMR, electronic medical record; FI, financial incentives; INT, intention to use EMR; PEOU, perceived ease of use; PU, perceived usefulness.

Table 3 AVE and correlation among constructs

\begin{tabular}{|l|l|l|l|l|l|l|}
\hline & ATT & INT & FI & PEOU & PU & AVE \\
\hline ATT & 0.931 & & & & & 0.868 \\
\hline INT & 0.578 & 0.945 & & & & 0.894 \\
\hline FI & 0.804 & 0.487 & 0.948 & & & 0.899 \\
\hline PEOU & 0.867 & 0.520 & 0.760 & 0.959 & & 0.921 \\
\hline PU & 0.892 & 0.537 & 0.807 & 0.918 & 0.945 & 0.894 \\
\hline
\end{tabular}

Abbreviations: ATT, attitude toward using EMR; AVE, Average variance extracted; EMR, electronic medical record; FI, financial incentives; INT, intention to use EMR; PEOU, perceived ease of use; PU, perceived usefulness.

\section{Discussion}

The present study empirically validates the classical theory, TAM in a health care perspective by going a step further to examine the effect of the gender and clinical specialty on physicians' intention to use EMR. Physicians' resistance to using the EMR system appears as the critical barrier to attaining comprehensive interoperability and achieve the benefits that can be executed from EMR. Thus, identifying the factors affecting physicians' intention toward EMR use is important. As they are the major user-group of EMR use and their intention to use is the primary condition to ensure that the expected benefits will be materialized.

There was a significant positive association between PU and attitudes toward using EMR, supporting H1. It implies that if physicians believe EMR is useful in patients' care, then physicians develop a positive attitude toward using EMR. Given this, when developing the EMR system, the health care providers should focus on strengthening the usefulness of EMR; considerably improve the functions that must meet physicians' requirement to carry out the medical practice. This development can motivate physicians to use the system persistently and further improves their intention to use EMR. However, this finding is consistent with the finding of Taylor and Todd ${ }^{104}$ who also indicated that PU had both direct and 


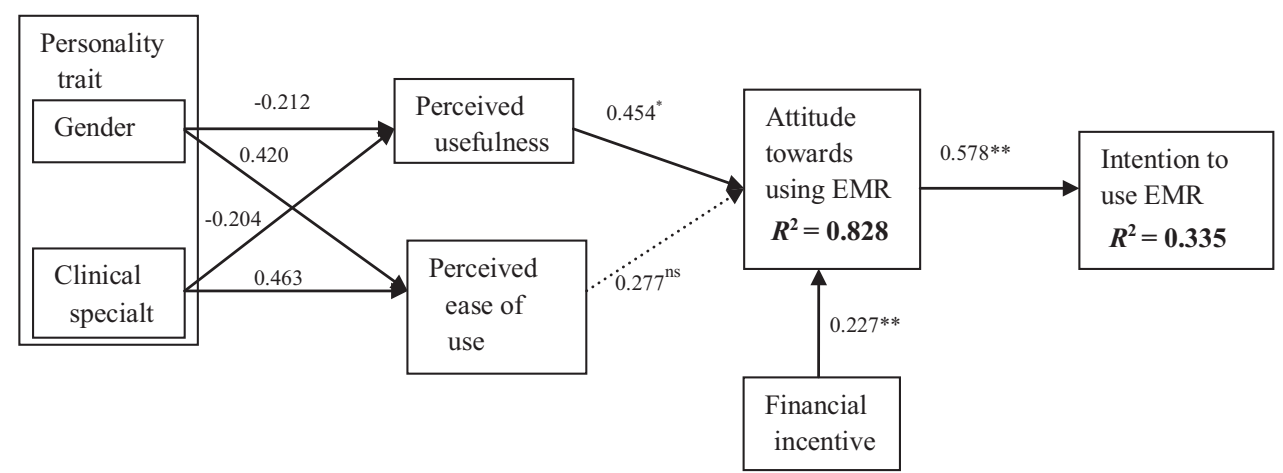

Fig. 2 Path analysis result. "Significant at $p<0.05$ level; $p<0.01^{* *}, p<0.001^{* * *}$. EMR, electronic medical record; NS, not significant at $p<0.05$ level.

Table 4 Results of the regression tests

\begin{tabular}{|l|l|l|}
\hline Path & $\beta$ & Results \\
\hline $\mathrm{PU} \rightarrow$ ATT & 0.454 & $\mathrm{H}_{1}$ : supported \\
\hline PEOU $\rightarrow$ ATT & 0.277 & $\mathrm{H}_{2}$ : not supported \\
\hline ATT $\rightarrow$ INT & 0.227 & $\mathrm{H}_{3}$ : supported \\
\hline $\mathrm{FI} \rightarrow$ ATT & 0.578 & $\mathrm{H}_{4}$ : supported \\
\hline Gender and clinical specialty differences \\
\hline Model 1: $F=14.749, d f=2 / 112, p=0.000<0.05$ \\
\hline $\begin{array}{l}\text { 1. Perceived usefulness }\left(R=0.457, R^{2}=0.208,\right. \\
\text { Durbin-Watson }=1.711)\end{array}$ & $\mathrm{H} 5:$ supported \\
\hline Gender & -0.212 & $\mathrm{H} 6:$ supported \\
\hline Clinical specialty & 0.420 & $\mathrm{H}$ : supported \\
\hline Model 2: $F=8.886, d f=2 / 112, p=0.000<0.05$ \\
\hline $\begin{array}{l}\text { 2. Perceived ease of use }\left(R=0.370, R^{2}=0.137,\right. \\
\text { Durbin-Watson }=1.858)\end{array}$ \\
\hline Gender & -0.204 & $\mathrm{H} 8:$ supported \\
\hline Clinical specialty & 0.463
\end{tabular}

Abbreviations: ATT, attitude toward using EMR; EMR, electronic medical record; INT, intention to use EMR; FI, financial incentives; PEOU, perceived ease of use; $\mathrm{PU}$, perceived usefulness.

indirect influences on the attitude toward using the system. Conversely, PEOU was negatively correlated with attitude toward using EMR, consistent with the previous study using the physician as subject. ${ }^{25}$ Therefore, $\mathrm{H} 2$ was not supported. The EMR is being used by physicians with a specific purpose to improve the quality of patients' care by increasing care coordination and eliminating errors; additionally, want to perform their medical practice more efficiently. So, physicians are mostly concerned about whether the services and contents offered by the EMR system are beneficial to improve their patients' care performance rather than feelings of easiness to operate the system. If physicians perceive that despite the system is easy to use, but did not improve their patients' care performance, then their attitude toward using EMR is not going to be improved anyway. Therefore, the difficulties with the system's interface or easiness to operate may possibly not be a significant consideration in patients' care perspective. Thus, the finding of the current study recommends that health care system developers should emphasize on the factors, physicians reasonably expecting from the EMR system, such as well-timed and necessary information for patients' care, authentic data regarding the patients' health condition, etc., could improve physicians' intention to use EMR.

In other words, the result from the nonsignificant relationship could be the combination of factors such as comprehensive computer literacy and small sample sizes. Physicians, on average, have a higher level of competency, intelligence, reasoning capacity, and skills to adopt new technologies. As a result of that, they are different from other user groups. Therefore, the variables of PEOU are still critical, but not significant $(p=0.07)$. Additionally, the small sample size limited the ability to detect a difference. Therefore, it is potential that a difference would have been noticed if the sample size was bigger. Thus, we suggest conducting more studies, especially enlarging the number of respondents.

The finding of the study revealed that attitude toward using EMR was positively associated with intention to use EMR, supporting H3. This finding is consistent with Davis ${ }^{70}$ and Chau and $\mathrm{Hu}^{25}$ The significant relationship between attitude and the use of EMR indicates that physicians evaluate the system positively. If physicians perceive a positive attitude toward using EMR system, their intentions of using EMR also improve. Thus, positive attitude should be considered as a strong determinant, while acceptance of the EMR system is concerned.

The results indicated that physicians place positive value regarding financial incentives, and it favorably affects attitude which indirectly influences physicians' intention to use EMR, supporting $\mathrm{H} 4$. However, financial incentives can positively change the physicians' attitudinal belief and form a positive attitude toward EMR usage. The finding of the current study is in line with the previous study finding by Cohen, ${ }^{105}$ which indicated that financial reward positively influenced physicians' perception toward using IS.

Previous studies based on TAM hypothesis stated that personality traits would moderate an individual's intention to use new Information Communication Technology (ICT) by persuading individuals' PU and PEOU. These variables might support researchers to understand the individual's adoption decision behavior. In the present study, it is theorized that 
personality traits, gender, and clinical specialty, mediate the relationships between an individual's belief (PU and PEOU) and future intention to use. Pijpers et al. ${ }^{106}$ also explored that the interpretation of the dynamics between mediating, independent, and dependent variables in TAM could result in better prediction of variables to intensify the intention to use emerging technologies.

Gender has recently appealed to the researchers' attention to study its influence on adoption behavior of individuals. ${ }^{80}$ Previous TAM studies addressed gender-based affective differences and their effects. Hoque ${ }^{30}$ thus hypothesized that males had a higher level of mHealth adoption intention than females. Though, empirical findings of the current study reported significant but negative, the relationship between gender (i.e., maleness), PU, and PEOU. It indicates that physicians consider a high degree of usefulness for health care technology, such as EMR. EMR influences actual usage of services within hospitals. Thus, physicians should be motivated to make use of EMR since it improves performance by decreasing errors and time necessary for treatment. Additionally, the finding indicates that physicians also demonstrate an understanding of EMR usage, along with its convenience, ease of use, and lack of technical difficulties; until they would like it to be usable. Physicians primarily have the key responsibility of treating patients and their time is limited. Thus, they want their association with technology to be uncomplicated. However, the negative relationship might be moderately attributed to the gender imbalance in the physician sample in the current study.

The current study found that the clinical specialty was the consistent predictor of physicians' PU and PEOU which also indirectly influences their intention to use EMR. The differences reported across specialties may be indicative of the emphasis that put on a certain type of practices. The potential factor in differing frequencies of EMR use among different specialties is that, until recently, many of the EMR systems tended to be "one-for-all" with features and tabs that might be effective for some specialties but not as efficient for others. ${ }^{107}$ In recent times, nevertheless, EMR developers have focused on developing more specialty specific EMR programs. However, it is still not well defined what influence these specific specialty programs will have on the implementation rate of EMR in the soon. Another contributing factor could be considering the perceptible requirement of all the proposed uses for an adaptable interface, presently used EMR only moderately fulfills the requirements of the different specialties. Thus, physicians' requirements should be carefully integrated during the development stages of EMR. The differences in preferences among different physicians indicate that different specialties have different needs during the implementation of innovations. Therefore, EMR system developers might use this finding to design the implementation trajectories to fit the needs of different physician specialties.

The present research contributes to theory and practice in several ways. First, the integrated model analyzed in the current study, combined elements of the TAM, context-specific variable financial incentives, and personality traits, gender, along with clinical specialty, has overcome the limited applicability of the TAM to study physicians' intention to use HIT. Additionally, the results of the study improve the current understanding in the field of technology acceptance and HIT implementation. Second, the study instrument not only contributes an overall assessment but also has the ability to examine what characteristics of the EMR (technology, behavioral, or user's specific differences) adoption are challenging from the physicians' perspective. Third, our extended TAM explains how differences in usage intention are influenced by EMR perception in physicians. The adoption theory evolved from the current study could be improved for application in large-scale services and organizations considering the adoption of EMR. Fourth, an understanding of the effects of gender differences on the intention to use EMR is important in overcoming barriers to the diffusion of technology across institutions. A consideration of the mechanisms through which gender differences impact technology usage behavior, is significant for trimming down resistance to technology use. Fifth, an understanding of the effects of clinical differences of physicians on the intention to use EMR is important in overcoming barriers to the diffusion of technology across the hospital and reducing the resistance to technology use. Sixth, as this study focuses on EMR use and unlike, studies examine behavioral intention; any development regarding the better understanding of phenomena can translate into higher acceptance and usage of the HIT after implementation. Finally, the results of the present study lead to better technology usage and can also have a better consideration for health care providers and policymakers before taking the decision about further spending on new HIT implementation.

\section{Limitations and Future Research}

Despite its significant findings and implications, two potential limitations of this study require consideration. First, the current study is one of the first employing gender and clinical specialty as antecedents and included a context-specific factor, clinical specialty with the classical model TAM to evaluate the physician's behavioral intention to use and adopt the EMR in Taiwan. In addition, the implications are from a single study with samples in Taiwan which may have led to institutional bias. Thus, researchers should be careful while generalizing the results to other health care circumstances. Future studies should conduct research in a nationwide perspective to explore and compare the differences in the antecedents to usage intention. Second, $56 \%$ of the eligible physicians participated in the survey. However, the response rate is reasonably acceptable in the perspective of physicians' HIS acceptance, but the sample size is moderately low. Relatively low sample size may have introduced selection bias, and we are not conclusive that the results of the study are representative of the entire population of physicians in Taiwan. Thus, the findings of this study can be used as the basis for a nationwide survey to enhance the external validity of those findings.

\section{Conclusions}

The current study examines critical factors influencing physicians' intention to use EMR through an integrated model derived from classical theory TAM with the attitudinal 
behavioral factor and financial incentives. Additionally, we explore the effect of gender and clinical specialty to confirm and expand the EMR system adoption model. Results from SEM analysis demonstrated that the model provided meaningful intuitions for perception, interpretation, anticipation, and presented good explanatory power to predict physicians' intention to use EMR, and providing a new direction for researchers to contemplate in subsequent research. The current study primarily identifies three relevant factors, that is, PU, financial incentives, and attitude toward using EMR, positively influencing physicians' intention to use EMR. Additionally, gender and clinical specialty differences are consistently found to predict both PU and PEOU which indirectly influence physicians' intention to use EMR.

Moreover, despite the small sample size, findings of the current study make a significant contribution in both academic and practical issues. Our study hospital is a typical regional teaching hospital with 654 beds, 213 physicians from different specialties, and fairly provides medical services to 650,000 patients annually. Thus, in terms of the number of beds, physicians, and outpatient services, we consider the findings of the current study are acceptable and external validity is also validated.

\section{Conflict of Interest}

None declared.

\section{References}

1 Scott RE. e-Records in health-preserving our future. Int J Med Inform 2007;76(5,6):427-431

2 AlHazme RH, Haque SS, Wiggin H, Rana AM. The impact of health information technologies on quality improvement methodologies' efficiency, throughput and financial outcomes: a retrospective observational study. BMC Med Inform Decis Mak 2016;16 (01):154

3 De Oliveira JF. The effect of the internet on the patient-doctor relationship in a hospital in the city of São Paulo. J Inf Syst Technol Manag 2014;11(02):327-344

4 Korgaonkar RB. Adoption of information system by Indian hospitals; challenges and roadmap. Int J Sci Eng Res 2014;5 (02):473-479

5 Alhamid SM, Lee DXY, Wong HM, et al. Implementing electronic handover: interventions to improve efficiency, safety and sustainability. Int J Qual Health Care 2016;28(05):608-614

$6 \mathrm{Su} \mathrm{CH}$, Li TC, Cho DY, et al. Effectiveness of a computerised system of patient education in clinical practice: a longitudinal nested cohort study. BMJ Open 2018;8(05):e020621

7 American Medical Association. Improving care: priorities to improve electronic health record usability. 2014. Available at: https://pdfs.semanticscholar.org/807e/09d1277e3a6032c893ea 47f445d06dc56f28.pdf?_ga =2.95001692.1959410284.15637823 50-1889254951.1561091521. Accessed July 22, 2019

8 Johnson RJ III. A comprehensive review of an electronic health record system soon to assume market ascendancy: EPIC. J Health Commun 2016;1(04):33-56

9 Greenhalgh T, Russell J, Ashcroft RE, Parsons W. Why national eHealth programs need dead philosophers: Wittgensteinian reflections on policymakers' reluctance to learn from history. Milbank Q 2011;89(04):533-563

10 Esmaeilzadeh P, Sambasivan M. Health Information Exchange (HIE): A literature review, assimilation pattern and a proposed classification for a new policy approach. J Biomed Inform 2016; 64:74-86
11 Ross J, Stevenson F, Lau R, Murray E. Factors that influence the implementation of e-health: a systematic review of systematic reviews (an update). Implement Sci 2016;11(01):146

12 Boonstra A, Versluis A, Vos JFJ. Implementing electronic health records in hospitals: a systematic literature review. BMC Health Serv Res 2014;14(370):370

13 Gagnon MP, Ghandour K, Talla PK, et al. Electronic health record acceptance by physicians: testing an integrated theoretical model. J Biomed Inform 2014;48:17-27

14 Ajami S, Bagheri-Tadi T. Barriers for adopting electronic health records (EHRs) by physicians. Acta Inform Med 2013;21(02): 129-134

15 O'Donnell A, Kaner E, Shaw C, Haighton C. Primary care physicians' attitudes to the adoption of electronic medical records: a systematic review and evidence synthesis using the clinical adoption framework. BMC Med Inform Decis Mak 2018;18(01):101

16 Sykes TA, Venkatesh V, Rai A. Explaining physicians' use of EMR systems and performance in the shakedown phase. JAm Med Inform Assoc 2011;18(02):125-130

17 Li J, Talaei-Khoei A, Seale H, Ray P, Macintyre CR. Health care provider adoption of eHealth: systematic literature review. Interact J Med Res 2013;2(01):e7

18 Al-Mujaini A, Al-Farsi Y, Al-Maniri A, Ganesh A. Satisfaction and perceived quality of an electronic medical record system in a tertiary hospital in oman. Oman Med J 2011;26(05):324-328

19 Melas CD, Zampetakis LA, Dimopoulou A, Moustakis V. Modeling the acceptance of clinical information systems among hospital medical staff: an extended TAM model. J Biomed Inform 2011;44 (04):553-564

20 Redd TK, Doberne JW, Lattin D, et al. Variability in electronic health record usage and perceptions among specialty vs. primary care physicians. AMIA Annu Symp Proc 2015;2015:2053-2062

21 Department of Health. 2003Online health services promotion plan- 2003 result report. Available at: http://www.doh.gov.tw/ CHT2006/DM/DM2_p01.aspx?class_no025\&now_fod_list_no09009\&level_no02\&doc_no041589. Accessed July 22, 2019

22 Fong BYF, Cheung WY, Ho SW, et al. Promoting electronic health record (eHR) sharing system in Hong Kong-what can we learn from Taiwan. Hong Kong Community College Working Paper Series 20159(03):

23 Hwang HG, Han HE, Kuo KM, Liu CF. The differing privacy concerns regarding exchanging electronic medical records of internet users in Taiwan. J Med Syst 2012;36(06):3783-3793

24 Department of Health. 2012. EMR Standard Management System. Available at: http://emr.doh.gov.tw/exProjects.aspx. Accessed July 22, 2019

25 Venkatesh V, Morris MG, Davis GB, Davis FD. User acceptance of information technology: toward a unified view. Manage Inf Syst Q 2003;27(03):425-478

26 Peek STM, Wouters EJM, van Hoof J, Luijkx KG, Boeije HR, Vrijhoef HJM. Factors influencing acceptance of technology for aging in place: a systematic review. Int J Med Inform 2014;83(04): 235-248

27 Klaus T, Blanton JE. User resistance determinants and the psychological contract in enterprise system implementations. Eur J Inf Syst 2010;19(06):625-636

28 Hu PJ, Chau PYK, Liu Sheng OR, Tam KY. Examining the technology acceptance model using physician acceptance of telemedicine technology. J Manage Inf Syst 1999;16(02):91-112

29 Chau PYK, Hu PJ. Examining a model of information technology acceptance by individual professionals: an exploratory study. J Manage Inf Syst 2002;18(04):191-229

30 Boonstra A, Broekhuis M. Barriers to the acceptance of electronic medical records by physicians from systematic review to taxonomy and interventions. BMC Health Serv Res 2010;10:231

31 Yi MY, Jackson JD, Park JS, Probst JC. Understanding information technology acceptance by individual professionals: toward an integrative view. Inf Manage 2006;43(03):350-363 
32 Chang I, Hwang HG, Hung WF, Li YC. Physicians' acceptance of pharmacokinetics-based clinical decision support systems. Expert Syst Appl 2007;33(02):296-303

33 Kijsanayotin B, Pannarunothai S, Speedie SM. Factors influencing health information technology adoption in Thailand's community health centers: applying the UTAUT model. Int J Med Inform 2009;78(06):404-416

34 Hoque MR. An empirical study of mHealth adoption in a developing country: the moderating effect of gender concern. BMC Med Inform Decis Mak 2016;16(51):51

$35 \mathrm{Kim} \mathrm{S}$, Lee KH, Hwang H, Yoo S. Analysis of the factors influencing healthcare professionals' adoption of mobile electronic medical record (EMR) using the unified theory of acceptance and use of technology (UTAUT) in a tertiary hospital. BMC Med Inform Decis Mak 2016;16:12

36 Al-Adwan AS, Berger H. Exploring physicians' behavioural intention toward the adoption of electronic health records: an empirical study from Jordan. Int J Healthc Technol Manag 2015;15(02):89

37 Liu CF, Cheng TJ. Exploring critical factors influencing physicians' acceptance of mobile electronic medical records based on the dual-factor model: a validation in Taiwan. BMC Med Inform Decis Mak 2015;15(01):4

38 Price AP. A study of factors influencing physician adoption of electronic medical records technology. In: Grenoble Ecole de Management. 2010

39 Podolny JM, James NB. Resources and relationships: social networks and mobility in the workplace. Am Sociol Rev 1997;62 (05):673-693

40 Hing E, Burt CW. Are there patient disparities when electronic health records are adopted? JHealth Care Poor Underserved 2009;20(02):473-488

41 Gillard H, Howcroft D, Mitev N, Richardson H. Missing women: gender, ICTs, and the shaping of the global economy. Inf Technol Dev 2008;14(04):262-279

42 Moffat MO, Moffat KJ, Cano V. General practitioners and the Internet-a questionnaire survey of Internet connectivity and use in Lothian. Health Bull (Edinb) 2001;59(02):120-126

43 Schwirian PM, Malone JA, Stone VJ, Nunley B, Francisco T. Computers in nursing practice. A comparison of the attitudes of nurses and nursing students. Comput Nurs 1989;7(04):168-177

44 Menon AS, Greenwald S, Ma TJ, Kooshesh S, Duriseti R. Patient and physician willingness to use personal health records in the emergency department. West J Emerg Med 2012;13(02):172-175

45 Chan T, de Lusignan S, Brew S. Overcoming the barriers to using information systems. Nurs Times 2004;100(49):44-46

46 Lai TYY, Leung GM, Wong IOL, Johnston JM. Do doctors act on their self-reported intention to computerize? A follow-up population-based survey in Hong Kong. Int J Med Inform 2004;73(05): 415-431

47 Loomis GA, Ries JS, Saywell RM Jr., Thakker NR. If electronic medical records are so great, why aren't family physicians using them? J Fam Pract 2002;51(07):636-641

48 Djalali S, Ursprung N, Rosemann T, Senn O, Tandjung R. Undirected health IT implementation in ambulatory care favors paper-based workarounds and limits health data exchange. Int J Med Inform 2015;84(11):920-932

49 Villalba-Mora E, Casas I, Lupiañez-Villanueva F, Maghiros I. Adoption of health information technologies by physicians for clinical practice: the Andalusian case. Int J Med Inform 2015;84 (07):477-485

50 Holanda AA, do Carmo E Sá HL, Vieira AP, Catrib AM. Use and satisfaction with electronic health record by primary care physicians in a health district in Brazil. JMed Syst 2012;36 (05):3141-3149

51 Chu RJ. How family support and Internet self-efficacy influence the effects of e-learning among higher aged adults: analyses of gender and age differences. Comput Educ 2010;55(01):255-264
52 Bhargava HK, Mishra AN. Electronic medical records and physician productivity: evidence from panel data analysis. Manage Sci 2014;60(10):2543-2562

53 Grinspan ZM, Banerjee S, Kaushal R, Kern LM. Physician specialty and variations in adoption of electronic health records. Appl Clin Inform 2013;4(02):225-240

54 Whitacre BE. The influence of the degree of rurality on EMR adoption, by physician specialty. Health Serv Res 2017;52(02):616-633

55 Grove DH, Patel V. Physician motivations for adoption of electronic health records. 2014.Available at: https://www.healthit.gov/sites/ default/files/oncdatabrief-physician-ehr-adoption-motivators2014.pdf. Accessed July 22, 2019

56 Clarke MA, Steege LM, Moore JL, Koopman RJ, Belden JL, Kim MS. Determining primary care physician information needs to inform ambulatory visit note display. Appl Clin Inform 2014;5(01): 169-190

57 Kingma M. Can financial incentive influence medical practice? Human Resources for Health Development Journal 1999; 3:121-131

58 National Health Statistics Group. Statistical abstract of the United States. 1999. Available at: https://www.census.gov/library/publications/1999/compendia/statab/119ed.html. Accessed July 22, 2019

59 Santerre RE, Neun SP. Health Economics: Theories, Insights, and Industry Studies. Orlando,FL: South-Western College Publishing; 2000

60 Roski J, Jeddeloh R, An L, et al. The impact of financial incentives and a patient registry on preventive care quality: increasing provider adherence to evidence-based smoking cessation practice guidelines. Prev Med 2003;36(03):291-299

61 Gosden T, Sibbald B, Williams J, Petchey R, Leese B. Paying doctors by salary: a controlled study of general practitioner behaviour in England. Health Policy 2003;64(03):415-423

62 Baron RJ, Fabens EL, Schiffman M, Wolf E. Electronic health records: just around the corner? Or over the cliff?. Ann Intern Med 2005;143(03):222-226

63 Marshall M, Harrison S. It's about more than money: financial incentives and internal motivation. Qual Saf Health Care 2005;14 (01):4-5

64 Miller R, Sim I, Newman J. Electronic medical records: Lessons from small physician practices. 2003. Available at: http://www. chcf.org/documents/ihealth/EMRLessonsSmallPhyscianPractices. pdf

65 New EMR Adopter Funding Program. 2013. Available at: www. ontariomd.ca/portal/server.pt/community/emr_funding/new_em radopters

66 Burt CW, Sisk JE. Which physicians and practices are using electronic medical records? Health Aff (Millwood) 2005;24 (05):1334-1343

67 Conrad DA, Perry L. Quality-based financial incentives in health care: can we improve quality by paying for it? Annu Rev Public Health 2009;30:357-371

68 Weisbrod Burton A. The health care quadrilemma: an essay on technological change, insurance, quality of care, and cost containment. JEcon Lit 1991;29(02):523-552

69 Chandra A, Jonathan SS. Technology growth and expenditure growth in health care. Available at: https://www.nber.org/ papers/w16953.pdf. Accessed July 22, 2019

70 Davis FD. Perceived usefulness, perceived ease of use, and user acceptance of information technology. Manage Inf Syst Q 1989; 13(03):319-340

71 Yarbrough AK, Smith TB. Technology acceptance among physicians: a new take on TAM. Med Care Res Rev 2007;64(06):650-672

72 Holden RJ, Karsh BT. The technology acceptance model: its past and its future in health care. JBiomed Inform 2010;43(01):159-172

73 Aggelidis VP, Chatzoglou PD. Using a modified technology acceptance model in hospitals. Int J Med Inform 2009;78(02):115-126 
74 Kuo KM, Liu CF, Ma CC. An investigation of the effect of nurses' technology readiness on the acceptance of mobile electronic medical record systems. BMC Med Inform Decis Mak 2013;13:88

75 Ryu S, Ho SH, Han I. Knowledge sharing behavior of physicians in hospitals. Expert Syst Appl 2003;25(01):113-122

76 Hung SY, Ku YC, Chien JC. Understanding physicians' acceptance of the Medline system for practicing evidence-based medicine: a decomposed TPB model. Int J Med Inform 2012;81(02):130-142

77 Miller RH, Sim I. Physicians' use of electronic medical records: barriers and solutions. Health Aff (Millwood) 2004;23(02): $116-126$

78 Vishwanath A, Scamurra SD. Barriers to the adoption of electronic health records: using concept mapping to develop a comprehensive empirical model. Health Informatics J 2007;13 (02):119-134

79 Patel V, Abramson EL, Edwards A, Malhotra S, Kaushal R. Physicians' potential use and preferences related to health information exchange. Int J Med Inform 2011;80(03):171-180

80 Venkatesh V, Morris MG. Why don't men ever stop to ask for directions? gender, social influence, and their role in technology acceptance and usage behavior. Manage Inf Syst Q 2000;24(01): 115-139

81 Nai L, Gill K. Gender and cultural differences in Internet use: A study of China and the UK. Comput Educ 2007;48(02):301-317

82 Nel J, Raleting T. Gender Differences in Non-Users' Attitude towards WIG Cellphone Banking 2010. Paper presented at the ANZMAC, University of Canterbury, Christchurch, New Zealand; 2010. Available at:http://anzmac2010.org/proceedings/pdf/anzmac10Final00038.pdf

83 Dutta B, Peng MH, Sun SL. Modeling the adoption of personal health record (PHR) among individual: the effect of health-care technology self-efficacy and gender concern. Libyan J Med 2018; 13(01):1500349

84 Alipour J, Erfannia L, Karimi A, Aliabadi A. Electronic health record acceptance: a descriptive study in Zahedan, Southeast Iran.J Health Med Inform 2013;4(02):. Doi: 10.4172/2157-7420.1000120

85 Chismar WG, Wiley-Patton S. Does the extended technology acceptance model apply to physicians. In System Sciences, 2003. Proceedings of the 36th Annual Hawaii International Conference on $2003 ; 8$

86 Alharthi H, Youssef A, Radwan S, Al-Muallim S, Zainab AT. Physician satisfaction with electronic medical records in a major Saudi Government hospital. Journal of Taibah University Medical Sciences 2014;9(03):213-218

87 Lin C, Lin IC, Roan J. Barriers to physicians' adoption of healthcare information technology: an empirical study on multiple hospitals. J Med Syst 2012;36(03):1965-1977

88 Dünnebeil S, Sunyaev A, Blohm I, Leimeister JM, Krcmar H. Determinants of physicians' technology acceptance for e-health in ambulatory care. Int J Med Inform 2012;81(11):746-760

89 Lakbala P, Dindarloo K. Physicians' perception and attitude toward electronic medical record. Springerplus 2014;3:63

90 Lakbala P, Lakbala M, Inaloo KD. Factors affecting electronic medical record acceptance by specialist physicians. Lecture Notes Information Theory 2014;2(04):316-321

91 Horan TA, Tulu B, Hilton B, Burton J. Use of Online Systems in Clinical Medical Assessments: An Analysis of Physician Accep- tance of Online Disability Evaluation Systems. Proceedings of the 37th Hawaii International Conference on System Sciences - 2004

92 Huang WM, Shih CT. An empirical study on the intentions of physicians in adopting electronic medical records with modified technology acceptance models in rural areas of Taiwan. Available at: https://pdfs.semanticscholar.org/6a34/b33bc9ec818acbbee24 b2b8f6fa246efa9aa.pdf?_ga=2.66279534.1959410284.15637823 50-1889254951.1561091521. Accessed July 22, 2019

93 Alasmary M, El Metwally A, Househ M. The association between computer literacy and training on clinical productivity and user satisfaction in using the electronic medical record in Saudi Arabia. J Med Syst 2014;38(08):69

94 Khorma OT, Baharom F, Mohd H. Construction of extended technology acceptance model of electronic medical records in jordan: the influence of doctors' self-efficacy and perceived behavioral control. Available at: https://pdfs.semanticscholar.org/8ecf/95986 fa9c688c5332b52e33b85d242fa2d85.pdf?_ga=2.41661666.1959 410284.1563782350-1889254951.1561091521. Accessed July 22, 2019

95 Liu HY, Liu CC, Shen TH, et al. Pattern of Visits to Older Family Physicians in Taiwan. Int J Environ Res Public Health 2017;14 (05):499

96 Taiwan Medical Association. 2017http://www.tma.te/stats/ indexNYearInfo.asp?/2017.html. Accessed July 22, 2019

97 Hair JF, Anderson RE, Tatham RL, Black W. Multivariate Data Analysis. 5th ed. NJ: Prentice-Hall, Inc; 1998

98 Hair JF, Ringle CM, Sarstedt M. PLS-SEM: indeed a silver bullet. J Mark Theory Pract 2011;19(02):139-152

99 Anderson JC, Gerbing DW. Structural equation modeling in practice: a review and recommended two step approach. Psychol Bull 1998;103(03):411-423

100 Nunnally JC. Psychometric Theory. New York, NY: McGraw-Hill; 1967

101 Streiner DL. Starting at the beginning: an introduction to coefficient alpha and internal consistency. J Pers Assess 2003;80(01): 99-103

102 Bagozzi RP, Yi Y. On the evaluation of structural equation models. JAcad Mark Sci 1988;16(01):74-94

103 Fornell C, Larcker DF. Evaluating structural equation models with unobservable variables and measurement error. JMark Res 1981;18(01):39-50

104 Taylor S, Todd P. Understanding information technology usage: A test of competing models. Inf Syst Res 2001;6(02):144-176

105 Cohen MF. Impact of the HITECH financial incentives on EHR adoption in small, physician-owned practices. Int J Med Inform 2016;94:143-154

106 Pijpers GGM, Bemelmans TMA, Heemstra FJ, van Montfort KAGM. Senior executives' use of information technology. Inf Softw Technol 2001;43(15):959-971

107 Hsiao CJ, Decker SL, Hing E, Sisk JE. Most physicians were eligible for federal incentives in 2011, but few had EHR systems that met meaningful-use criteria. Health Aff (Millwood) 2012;31(05): $1100-1107$

108 National Health Care Purchasing Institute. Bailit Health Purchasing, LLC, Sixth Man Consulting, Inc. An Initiative of The Robert Wood Johnson Foundation. 2001https://www.ncbi.nlm. nih.gov/nlmcatalog/101192311 
Appendix A Measurement items

\begin{tabular}{|c|c|c|c|}
\hline Construct & Item no. & Item & References \\
\hline \multirow{7}{*}{$\begin{array}{l}\text { Perceived } \\
\text { usefulness } \\
\text { (PU) }\end{array}$} & PU1 & $\begin{array}{l}\text { I expect using EMR will improve the quality of my job to provide better } \\
\text { patient care }\end{array}$ & \multirow[t]{7}{*}{ Davis $^{70}$} \\
\hline & PU2 & I believe using EMR will allow me to better control over my work schedule & \\
\hline & PU3 & I expect using EMR would allow me to finish task more quickly & \\
\hline & PU4 & $\begin{array}{l}\text { I expect using EMR would allow me to finish more task within my work } \\
\text { schedule than before }\end{array}$ & \\
\hline & PU5 & I believe using EMR would improve my overall usefulness in my job. & \\
\hline & PU6 & I expect using the EMR would make my job easier to complete. & \\
\hline & PU7 & Overall, practicing EMR would be a useful tool in my profession & \\
\hline \multirow{4}{*}{$\begin{array}{l}\text { Perceived } \\
\text { ease of use } \\
\text { (PEOU) }\end{array}$} & PEOU1 & I think that my interaction with EMR would be clear and understandable & \multirow[t]{4}{*}{ Davis $^{70}$} \\
\hline & PEOU2 & I expect learning of EMR would be easy for me & \\
\hline & PEOU3 & I believe that I would be skillful of using EMR & \\
\hline & PEOU4 & Overall, I expect that use of EMR will be easy for physician & \\
\hline \multirow{6}{*}{$\begin{array}{l}\text { Attitude } \\
\text { toward } \\
\text { using EMR } \\
\text { (ATT) }\end{array}$} & ATT1 & $\begin{array}{l}\text { The implementation of the EMR will support the physician in providing } \\
\text { better patient care }\end{array}$ & \multirow[t]{6}{*}{ Davis $^{70}$} \\
\hline & ATT2 & I will encourage my colleague to use the EMR & \\
\hline & ATT3 & I need EMR system to provide effective patient care & \\
\hline & ATT4 & I am not satisfied with using the paper-based patient record in my job & \\
\hline & ATT5 & All physicians should learn to use EMR successfully & \\
\hline & ATT6 & Overall, my attitude about EMR has been positive & \\
\hline \multirow{5}{*}{$\begin{array}{l}\text { Financial } \\
\text { incentives } \\
\text { (FI) }\end{array}$} & $\mathrm{Fl1}$ & The size of the financial incentive & \multirow{5}{*}{$\begin{array}{l}\text { National Health Care } \\
\text { Purchasing Institute }\end{array}$} \\
\hline & $\mathrm{FI} 2$ & The incentive and need for change recognized among physicians & \\
\hline & $\mathrm{FI3}$ & The level of support for the incentive program in the medical leadership & \\
\hline & $\mathrm{Fl4}$ & $\begin{array}{l}\text { The practicing physicians' knowledge and understanding of the perfor- } \\
\text { mance incentives }\end{array}$ & \\
\hline & $\mathrm{FI5}$ & Overall, financial incentive encourages physician's decision to use EMR & \\
\hline \multirow{4}{*}{$\begin{array}{l}\text { Intention } \\
\text { to use EMR } \\
\text { (INT) }\end{array}$} & INT1 & $\begin{array}{l}\text { When it is available in my clinical practice, I intend to use EMR for all my } \\
\text { clinical activities }\end{array}$ & \multirow[t]{4}{*}{ Davis $^{70}$} \\
\hline & INT2 & $\begin{array}{l}\text { When it is available in my organization, I intend to adopt EMR for all my } \\
\text { clinical activities }\end{array}$ & \\
\hline & INT3 & $\begin{array}{l}\text { The probabilities that I use EMR for all my clinical activities when available in } \\
\text { my organization are very high }\end{array}$ & \\
\hline & INT4 & $\begin{array}{l}\text { Whatsoever the environments, I do not intend to use EMR when it becomes } \\
\text { available in my organization }\end{array}$ & \\
\hline
\end{tabular}

Abbreviation: EMR, electronic medical record. 
Appendix B Results of confirmatory factor analysis and reliability analysis

\begin{tabular}{|c|c|c|c|}
\hline Constructs & Item & Loadings & Standardized Cronbach's $\alpha$ \\
\hline \multirow[t]{7}{*}{ Perceived usefulness (PU) } & PU1 & 0.908 & \multirow[t]{7}{*}{0.965} \\
\hline & PU2 & 0.919 & \\
\hline & PU3 & 0.841 & \\
\hline & PU4 & 0.915 & \\
\hline & PU5 & 0.949 & \\
\hline & PU6 & 0.905 & \\
\hline & PU7 & 0.934 & \\
\hline \multirow[t]{4}{*}{ Perceived ease of Ease (PEOU) } & PEOU1 & 0.927 & \multirow[t]{4}{*}{0.955} \\
\hline & PEOU2 & 0.932 & \\
\hline & PEOU3 & 0.934 & \\
\hline & PEOU4 & 0.961 & \\
\hline \multirow[t]{6}{*}{ Attitude toward using EMR (ATT) } & ATT1 & 0.965 & \multirow[t]{6}{*}{0.965} \\
\hline & ATT2 & 0.983 & \\
\hline & ATT3 & 0.823 & \\
\hline & ATT4 & 0.868 & \\
\hline & ATT5 & 0.919 & \\
\hline & ATT6 & 0.983 & \\
\hline \multirow[t]{5}{*}{ Financial incentives (FI) } & $\mathrm{Fl} 1$ & 0.922 & \multirow[t]{5}{*}{0.970} \\
\hline & $\mathrm{FI} 2$ & 0.978 & \\
\hline & $\mathrm{FI3}$ & 0.902 & \\
\hline & $\mathrm{Fl} 4$ & 0.956 & \\
\hline & $\mathrm{FI5}$ & 0.963 & \\
\hline \multirow[t]{4}{*}{ Intention to use EMR (INT) } & INT1 & 0.850 & \multirow[t]{4}{*}{0.893} \\
\hline & INT2 & 0.811 & \\
\hline & INT3 & 0.875 & \\
\hline & INT4 & 0.823 & \\
\hline
\end{tabular}

Abbreviation: EMR, electronic medical record. 